\title{
A educação sob o impacto da pandemia Covid-19: uma discussão da literatura
}

\section{The impact of the Covid-19 pandemic on education: a literature review}

\author{
${ }^{1}$ Maria Iolanda Fontana maria.iolanda.fontana@gmail.com \\ ${ }^{1}$ Maria Arlete Rosa \\ ${ }^{2}$ Samira Kauchakje
}

\section{RESUMO}

Este artigo discute a educação no contexto da pandemia - Covid 19. O objetivo é analisar problematizações e proposições, apontadas por pesquisadores, para o enfrentamento dos desafios do ensino remoto. O procedimento metodológico utilizado foi a busca sistemática e a seleção qualitativa de textos sobre o tema. A análise dos artigos indica que a crise gerada pela pandemia possibilitou uma oportunidade para professores desenvolverem recursos pedagógicos em plataformas virtuais para planejar e desenvolver aulas remotas. Ainda, representou uma oportunidade para os empresários da educação comercializarem plataformas e outras tecnologias de informação e comunicação, assim como demandou a adaptação compulsória de professores, alunos e técnicos envolvidos para garantir os conteúdos pedagógicos nos cursos presenciais e fortalecer sua transformação em modalidade em EaD ou semipresencial. São duas oportunidades em disputa, uma pela disseminação de uma modalidade a distância a partir do aprimoramento destas plataformas de ensino virtual, alavancadas pela força do experimento real, e a outra para os interessados na educação como bem do mercado. Para a manutenção da modalidade presencial, a mobilização da comunidade acadêmica faz-se necessária para garantir as condições de qualidade do ensino e não precarização do trabalho docente.

Palavras-chave: Educação. Pandemia Covid-19. Tecnologias. Ensino Remoto.

\begin{abstract}
This article discusses education in the context of the Covid-19 pandemic. The aim is to analyze problems and proposals suggested by researchers to face the challenges of remote teaching. The research methodology involved the systematic and qualitative selection of texts about the theme. The analysis of articles indicates that the crisis generated by the pandemic provided the opportunity for teachers to develop pedagogical resources in virtual platforms to plan and teach remote classes. In addition, the pandemic represented an opportunity for education entrepreneurs to commercialize platforms and other information and communication technologies. The pandemic also forced teachers, students and technicians to adapt to assure the pedagogical contents in face to face courses and strengthen its transformation into remote or semi-remote education. There are two opportunities at stake, the dissemination of remote teaching/learning based on the improvement of the virtual teaching platforms, motivated by the real experience and another for those interested in education as well as in business. In order to maintain the face to face modality, the mobilization of the academic community is essential to guarantee the quality of teaching and avoid the precariousness of teachers' work.
\end{abstract}

Keywords: Education. Covid-19 Pandemic. Technologies. Remote Teaching.

\footnotetext{
1 Universidade Tuiuti do Paraná - UTP

2 Universidade do Estado de Santa Catarina - UDESC
} 


\section{INTRODUÇÃO}

O estado de pandemia ocasionado pelo novo Coronavírus COVID-19 e a necessidade do distanciamento social como estratégia de saúde pública para reduzir o contágio têm agravado problemas políticos, econômicos e sociais, desencadeados pelo ideário neoliberal, em acirramento nas últimas três décadas. Conforme analisa Mattei (2020), trata-se de uma crise sanitária de proporção global, distinta de outras crises derivadas do funcionamento das estruturas econômicas. Esta conjuntura demanda medidas urgentes para conter a pandemia e buscar estimular a economia para evitar o caos econômico e social, o que reforça a "importância do Estado enquanto agente decisivo para implementar políticas efetivas capazes de reaquecer as atividades econômicas” (MATTEI, 2020, p.3).

Na pandemia, o distanciamento social como medida de segurança desencadeou impactos na educação escolar, como a suspensão das aulas nos diferentes níveis e modalidades de ensino e a regulamentação do ensino remoto, em acordo com as orientações expressas em documentos relacionados a educação ${ }^{3}$ elaborados por organismos internacionais ligadas à Organização das Nações Unidades - Organização Mundial de Saúde (OMS), Fundo das Nações Unidas para a Infância (Unicef) e Organização das Nações Unidas para a Educação, a Ciência e a Cultura (Unesco).

A disseminação da modalidade de ensino a distância, a partir do aprimoramento de plataformas de ensino virtual, alavancou a oportunidade para os interessados na educação como bem de mercado e criou impasses, principalmente, para professores e alunos das escolas públicas, pela dificuldade de acesso a estes recursos. Assim, a reorganização da dinâmica escolar por meio remoto privou os estudantes da educação básica e superior do convívio social e desencadeou contradições e tensões, que necessitam ser discutidas. Destacam-se como imprescindíveis as discussões sobre: a vulnerabilidade social e a democratização do acesso à internet e tecnologias digitais, a desvalorização e intensificação do trabalho docente (BARRETO; ROCHA, 2020), a ressignificação dos conceitos de distância e de ensino e o novo paradigma da educação semipresencial (MARTINS, 2020).

Novas normatizações foram estabelecidas pelo Conselho Nacional de Educação (CNE) para atender demandas da excepcionalidade do estado de pandemia. O Conselho Nacional de Educação emitiu a Nota de Esclarecimento, em 18 de março de 2020, sobre "as implicações da pandemia da COVID-19 no fluxo do calendário escolar" (BRASIL, 2020a) e flexibilizou as normas e os parâmetros legais estabelecidos, orientando que "as redes e instituições de educação básica e educação superior podem propor formas de realização e reposição de dias e horas de efetivo trabalho escolar” (BRASIL, 2020a). Estabeleceu, a partir da Medida Provisória n. ${ }^{\circ}$ 934, de $1^{\circ}$ de abril de 2020, normas excepcionais sobre o ano letivo da educação básica e do ensino superior decorrentes das medidas para enfrentamento da situação de emergência de saúde pública de que trata a Lei $n^{\circ} 13.979$, de 6 de fevereiro de 2020 (BRASIL, 2020b). O Parecer do CNE nº 5, de 28 de abril de 2020, explicitou que a realização das atividades pedagógicas não presenciais se caracteriza pela mediação de tecnologias digitais ou não, podendo acontecer por meio de programas de televisão, de rádio, pela adoção de material didático impresso com orientações pedagógicas distribuído aos alunos e seus pais ou responsáveis, e pela orientação de leituras, projetos, pesquisas, atividades e exercícios indicados nos materiais didáticos (BRASIL, 2020c). Estas normatizações permitem reorganizações não padronizadas dos calendários escolares, por meio de atividades pedagógicas não presenciais no âmbito dos sistemas de ensino dos estados e municípios da federação nacional.

A gestão das escolas, das universidades e seus educadores buscou alternativas para garantir a educação como um direito constitucional a todos os estudantes, como também a qualidade das aprendizagens. Surgem

3 Documento publicado pela Organização Mundial da Saúde, em 10 de maio de 2020 (Considerações para medidas de saúde pública relacionadas a escolas no contexto da COVID-19). Este documento foi substituído, em 14 de setembro, pelo elaborado (Considerações para o ajuste de medidas sociais e de saúde pública no contexto da COVID-19), com a contribuição do Grupo Técnico Consultivo de Especialistas em Instituições de Ensino e COVID-19 e especialistas da OMS, Unicef e Unesco. O propósito é ajudar elaboradores de políticas e educadores a tomarem decisões sobre a forma mais segura de gerir escolas durante a pandemia de COVID-19, visando a continuidade da educação e a garantia do bem-estar geral, da saúde e da segurança dos estudantes. Disponível em: https://iris.paho.org/bitstream/handle/10665.2/52682/OPASWBRACOVID-1920112_por.pdf?sequence=5\&isAllowed=y. Acesso em: 20 out. 2020. 
muitos debates em torno do assunto veiculados em artigos, lives, dossiês, manifestos veiculados por entidades representativas dos educadores ${ }^{4}$ que contribuem para a interlocução entre pesquisadores, professores, gestores da educação, fóruns de educação, entidades sindicais e movimentos sociais.

O sistema de ensino remoto desencadeou problemas de natureza socioeconômica, política, pedagógica, tecnológica e de saúde, no contexto da nova configuração da educação básica e superior. Entre os problemas, são enfatizados: a falta de acesso às tecnologias digitais e rede de internet; a intensificação do trabalho dos profissionais da educação; políticas não democráticas de ensino remoto adotadas pelos sistemas de ensino; desigualdade social em relação às políticas de avaliação em larga escala; os investimentos na substituição do sistema presencial pelo ensino a distância; as dificuldades das famílias na tutoria dos estudos das crianças e adolescentes de forma remota e no acesso aos meios virtuais de comunicação, além da tensão e do adoecimento emocional de professores, familiares e alunos. Também, pesquisadores, como Santana Filho (2020), alertam para o risco de políticas educacionais aligeiradas que desviam investimentos para empresas privadas subsidiarem recursos tecnológicos, canais de televisão e compra de materiais pedagógicos. Situação condizente com o mercado como princípio prioritário e a privatização como a lógica de mercado, assim surgem as "parcerias público-privadas, quase sempre um mecanismo de transferência de recursos públicos para o setor privado” (SANTOS, 2020, p.27-28).

Neste contexto, o objetivo deste artigo é analisar as problematizações e proposições, apontadas por pesquisadores, para o enfrentamento dos desafios do ensino remoto. Para tanto, foi realizado um levantamento das publicações sobre a Covid-19 nas bases de busca Scopus, Web of Science, Scielo e Google Scholar, e em um Dossiê sobre o tema publicado na Revista Educação Básica em Foco, da Associação Nacional de Política e Administração da Educação (ANPAE). A partir deste levantamento, foram selecionadas três categorias de análise para compreensão das problematizações do ensino remoto na educação brasileira: as tecnologias digitais, políticas de ensino remoto e trabalho docente.

O artigo está estruturado em três partes: a primeira trata dos resultados da revisão sistemática da literatura; na segunda parte, a discussão sobre os achados na revisão de literatura, seguida de síntese conclusiva, nas considerações finais.

\section{METODOLOGIA}

O método utilizado combinou recursos de busca da revisão sistemática da literatura e a seleção e análise qualitativa de textos nas bases de dados do Google Scholar e o Dossiê sobre o tema publicado na Revista Educação Básica em Foco, da Associação Nacional de Política e Administração da Educação (ANPAE), conforme apresentados a seguir.

\section{a. Busca sistemática da literatura}

Para a busca sistemática nas bases bibliográficas que indexam textos, foram realizados testes de termos (string de busca) para serem aplicados e os que devolveram resultados mais aderentes aos objetivos propostos estão descritos na Tabela 1.

4 A exemplo do manifesto sobre o " Posicionamento sobre o Parecer do CNE que trata da Reorganização dos Calendários Escolares e a realização de atividades pedagógicas não presenciais durante o período de Pandemia da COVID-19” elaborado por 17 entidades, entre elas: ANPEd - Associação Nacional de Pós-Graduação e Pesquisa em Educação ANPAE -Associação Nacional de Política e Administração da Educação ANFOPE - Associação Nacional pela Formação dos Profissionais da Educação ABdC - Associação Brasileira de Currículo ABRAPEC - Associação Brasileira de Pesquisa em Educação em Ciências. Disponível em: http://www.anfope.org.br/wp-content/uploads/2020/04/1.-Nota-das-entidades-nacionais-ref-Parecer-COVID-19.pdf Acesso em: 25 out. 2020. 
Tabela 1 - Definições operacionais da busca sistemática da literatura

Bases bibliográficas Scopus; Web of Science, Scielo e Google Acadêmico

\begin{tabular}{lr}
\hline $\begin{array}{l}\text { String de busca } \\
\text { (Scopus e WoS) }\end{array}$ & $\begin{array}{c}((\text { teach* OR educat* OR school* OR college* OR universit*) AND (covid-19 OR } \\
\text { covid-19 OR “corona virus” OR coronavirus) ) ) }\end{array}$ \\
\hline $\begin{array}{l}\text { String de busca } \\
\text { Scielo }\end{array}$ & $\begin{array}{c}\text { ((“teaching-learning” OR teach* OR learn* OR educat*) AND ( covid-19 OR } \\
\text { corona virus” OR coronavirus) })\end{array}$ \\
\hline $\begin{array}{l}\text { String de busca Google } \\
\text { scholar }\end{array}$ & $(($ ensino OR educaçao) AND (coronavirus OR “covid-19”)) \\
\hline
\end{tabular}

Línguas selecionadas Inglês, espanhol e português

Áreas de conhecimento Ciências Humanas, Ciências Sociais, Educação e outras áreas com interface com Educação*

\begin{tabular}{ll}
\hline Tipo de lista (ordenamento & $\begin{array}{c}\text { mais citados (exceto para Google Scholar que ordena os resultados pelo critério de } \\
\text { dos resultados) }\end{array}$ \\
\hline
\end{tabular}

Período 2019-2020

Fonte: As autoras

A partir da aplicação dessas definições operacionais de busca sistemática da literatura, foi gerada uma lista de 253 artigos na base Scopus; 177 na WoS; 2 na Scielo citation index e 1.770 resultados na base Google Scholar.

Desse total, fizemos uma pré-seleção dos textos, conforme detalhado no item a seguir.

\section{b. Seleção qualitativa dos artigos e procedimentos para orientar a análise}

Para a pré-seleção dos artigos encontrados na base de buscas do Scopus, WoS e Scielo, realizamos a leitura dos títulos e das palavras-chave. Porém, quando esses procedimentos de leitura não foram suficientes, no sentido de trazer elementos que indicassem a adesão do artigo aos objetivos da pesquisa, a estratégia utilizada foi examinar os resumos. Excluídos os artigos que não apresentaram aderências, restaram 45 artigos extraídos da base Scopus, 32 da WoS; 01 da Scielo. Observamos que essa fase de pré-seleção é indicada pelas melhores práticas de revisão sistemática de literatura (O’BLENYS, 2017; OKOLI, 2019). Essa fase é desdobrada na análise ampliada de todos os resumos conforme os procedimentos subsequentes.

Com relação ao Google Scholar, tendo em vista o número elevado da lista de documentos, o critério de pré-seleção dos textos foi diferente ${ }^{5}$. Aplicamos a denominada "seleção prática”, por Okoli (2019, p.17-19). O autor alerta que esse tipo de seleção envolve a

5 Enquanto as bases de dados Scopus e WoS podem ordenar os documentos por ordem de citação, o Google Scholar o faz pela relevância. Relevância neste caso significa, entre outros critérios, ordenar a lista de documentos pela maior aderência aos termos escolhidos para a busca pelo número de acessos. 
[...] decisão de quais estudos devem ser considerados para a revisão. O objetivo da seleção prática é reduzir o número de estudos a serem analisados para o número com o qual os revisores possam lidar. Ressalto, particularmente, que essa determinação não se baseia em uma avaliação cuidadosa da qualidade dos documentos (que é um passo subsequente...), mais em considerações pragmáticas [...]

Em alinhamento com o pragmatismo da seleção prática, fizemos o recorte para a pré-avaliação dos 40 primeiros documentos listados no Google Scholar. Ainda, mais que esses textos se mostraram suficientes para trazer elementos que buscávamos para a análise.

Considerando esse novo conjunto de artigos de todas as bases de dados, totalizando 118 documentos, realizamos uma nova rodada de seleção, agora com o objetivo de comparar as listas geradas em cada base de busca. Com isso, concluímos que os artigos do Google Scholar eram mais compatíveis com a proposta deste trabalho. Diante disso, nossa escolha metodológica, por um lado, foi utilizar os dados bibliométricos das bases do Scopus, WoS e Scielo, uma vez que esses nos dão um panorama da produção sobre o tema (ver Figura 1 a 4). Por outro lado, decidimos mobilizar estratégias qualitativas, selecionando tão somente textos do Google Scholar, diante de sua maior adesão ao estudo. A esses documentos acrescentamos dossiê publicado pela ANPAE dedicado justamente ao tema de nosso trabalho: "Dossiê Educação em tempos de pandemia: vozes dos sujeitos da educação básica”, publicado na Revista Educação Básica em Foco (2020).

A partir dessa definição, realizamos os seguintes procedimentos:

- Refinamento da seleção pela leitura de todos os resumos dos textos pré-selecionados;

- Pré-análise dos resumos para identificar o conteúdo geral (tema, objetivos, metodologia e resultados). Esse momento contribuiu para refinar os textos selecionados no momento anterior;

- Leitura completa dos textos selecionados em definitivo para análise de conteúdo e categorização que produziu os resultados.

O critério qualitativo para a seleção dos artigos foi a pertinência ao debate, considerando a densidade teórico-metodológica desenvolvida pelos autores em relação às categorias: tecnologias digitais, políticas de ensino remoto e trabalho docente. Entende-se que analisar estas categorias de modo articulado pode favorecer a compreensão dos conflitos e contradições da educação brasileira no contexto da pandemia.

Foram levantados alguns questionamentos orientadores para a seleção dos artigos aderentes à elucidação das categorias, são eles: Como as instituições e sistemas de ensino resolvem o problema da falta de acesso às tecnologias digitais e internet de estudantes e professores? Os professores e alunos estão preparados para utilizar estas tecnologias? As famílias estão preparadas fazer a tutoria do ensino de seus filhos? As políticas educacionais estabelecidas pelos sistemas de ensino têm orientado medidas de democratização do acesso ao ensino remoto? Quais são as proposições para a superação de problemas e melhoria da aprendizagem no ensino remoto? Quais os impactos do ensino remoto ao trabalho docente? Quais metodologias de ensino remoto contribuem para a aprendizagem dos estudantes? Como avaliar os estudantes no sistema remoto de ensino?

A aplicação de tais critérios qualitativos resultou em 20 artigos selecionados na base de busca do Google Scholar e em 12 do Dossiê/ANPAE. Destacamos que as questões elencadas, também, nortearam a análise dos artigos, apresentada no item a seguir. 
Esta sessão apresenta o panorama quantitativo sobre as publicações em revistas indexadas que discutem o tema educação sob o impacto da pandemia ${ }^{6}$. Também, analisa o conteúdo dos artigos selecionados.

\section{a. Resultados bibliométricos}

Serão exploradas algumas medidas geradas pelas próprias bases bibliográficas e que fornecem um panorama geral da produção ${ }^{7}$. As métricas dos artigos selecionados das bases bibliográficas Scopus e WoS são equivalentes, demonstrando as preponderâncias dos periódicos dos Estados Unidos e outros países, principalmente de língua inglesa, assim como dos artigos nas áreas de Ciências Sociais e da Educação (Figuras 1 a 4):

Figura 1 - Documentos sobre impacto da pandemia da Covid-19 sobre a educação (maio 2020).

\section{Documents by country or territory}

Compare the document counts for up to 15 countries/territories.

\section{Scopus}

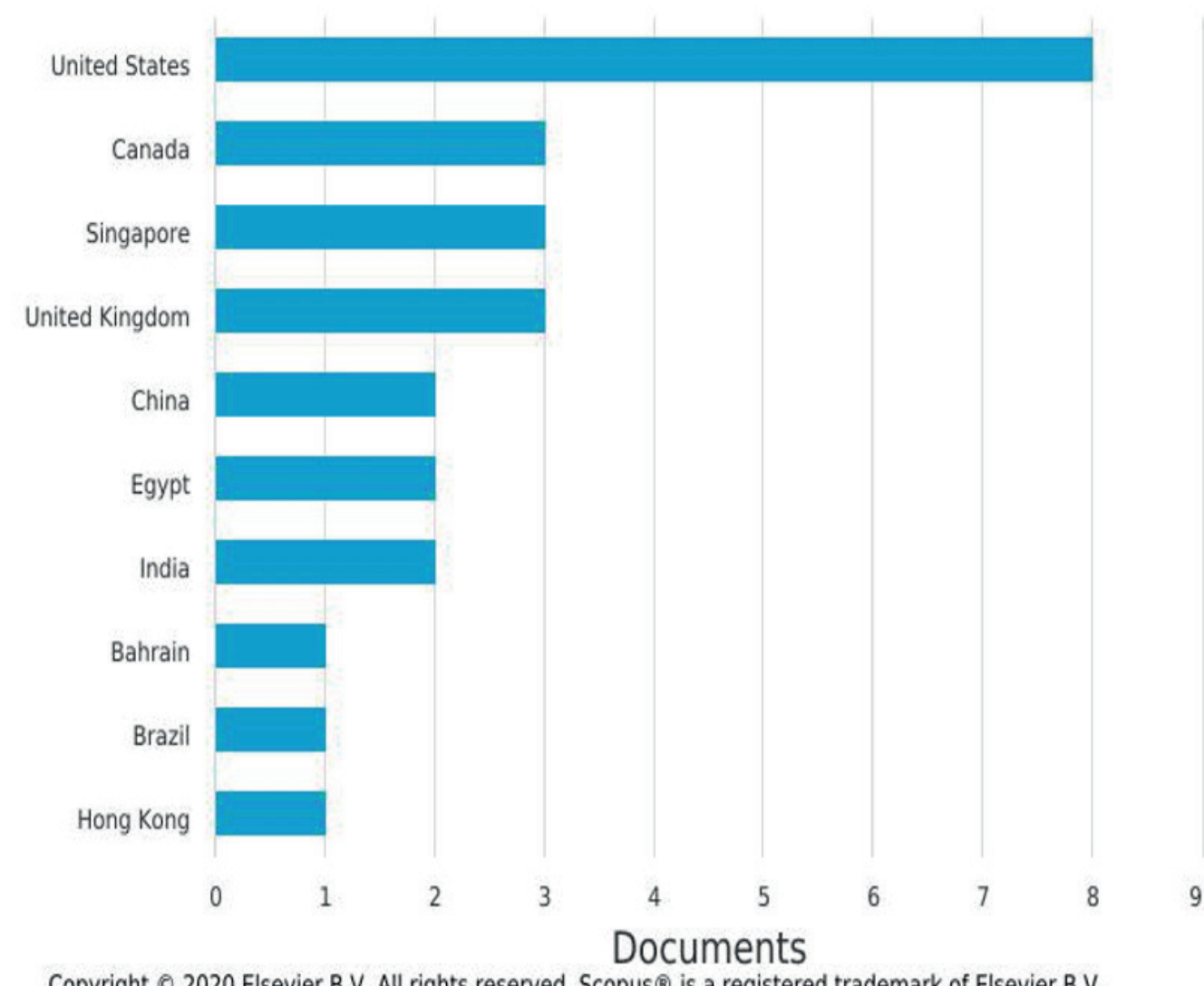

Copyright $\odot 2020$ Elsevier B.V. All rights reserved. Scopus $₫$ is a registered trademark of Elsevier B.V.

Fonte: Scopus - https://www.scopus.com/home.uri

6 Os dados bibliométricos deste estudo referem-se à pesquisa realizada até 20 de maio de 2020.

7 Os gráficos gerados pelas próprias bases bibliográficas, as quais seguem diferentes padrões de representação dos dados. Optamos por reproduzi-los mantendo seu formato original. 
Figura 2 - Documentos sobre impacto da pandemia da Covid-19 sobre a educação (maio 2020).

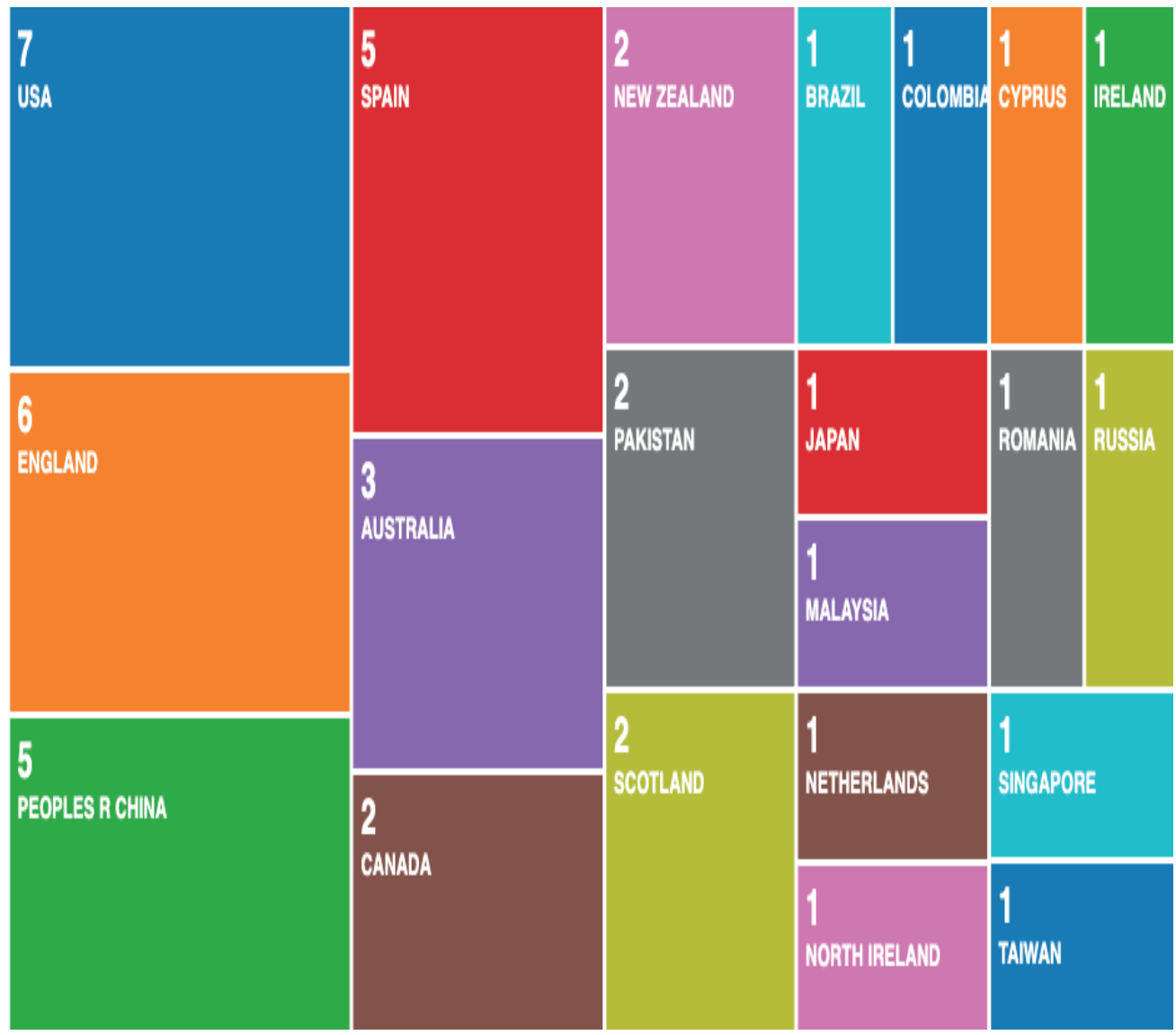

Fonte: Web of Science https://www.periodicos.capes.gov.br/?option=com_pcollection\&mn=70\&smn=79\&cid=81

Observa-se que a Organização Mundial da Saúde declarou a pandemia de Covid-19 na primeira quinzena de março de 2020. Após dois meses, os Estados Unidos registram o maior número de artigos articulando Covid-19 e educação, ao passo que o Brasil ficou entre os países que menos publicaram sobre esse tema, no período. Portanto, o predomínio de publicações qualificadas em países de maior desenvolvimento econômico (NEVES; SANNA, 2012) repete-se para publicações sobre o impacto da atual pandemia na educação. Isso se deve ao maior incentivo destes países em pesquisas e os próprios parâmetros de indexação de periódicos nessas bases de dados, tais como Scopus e WoS (SANTA et al., 2010; LUCIO-ARIA et al., 2016). Este cenário reflete o que Kauchakje e Rosa (2020, p.59) discutiram:

O viés “oculto” decorre do fato das principais bases científicas acionadas para realizar a revisão sistemática da literatura serem compostas por uma porcentagem alta de periódicos de instituições de língua inglesa do hemisfério norte, que incentivam a pesquisa e a publicação, reproduzindo, assim, a desigualdade na capacidade de produção de conhecimento de países economicamente menos desenvolvidos.

Com relação às áreas de conhecimento filtradas (Quadro 1) na base Scopus, o maior número de publicações (68,6\%) é de Ciências Sociais. É nessa grande área que os artigos sobre educação estão inseridos, isso porque, na base Scopus, não há a opção para subdividir as grandes áreas de classificação. Esse recurso está disponível na base WoS, por isso pode-se visualizar o maior número de textos sobre o tema publicados especificamente na área da educação, representando $61,7 \%$ do total. As métricas dos 32 artigos selecionados da base bibliográfica WoS além de demonstrar esta predominância de artigos na área da Educação, também evidenciam a preponderância de periódicos dos EUA e Inglaterra que tratam de aspectos educacionais sob o impacto da pandemia (Figura 3 e 4). 
Figura 3 - Documentos sobre impacto da pandemia da Covid-19 sobre a educação, por área de conhecimento (maio 2020).

Documents by subject area

Scopus

Social Sciences... (68.6\%)

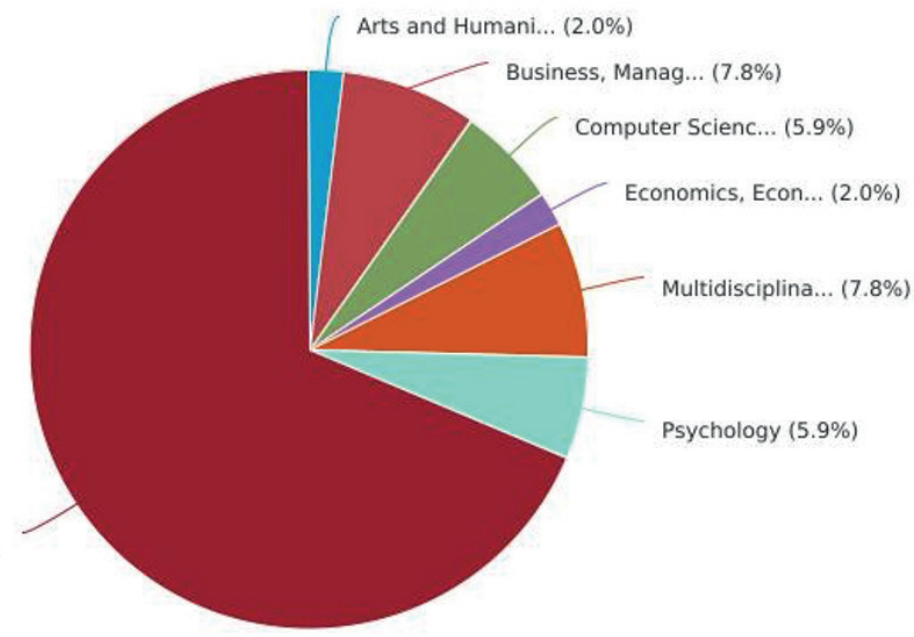

Copyright 2020 Elsevier B.V. All rights reserved. Scopus $®$ is a registered trademark of Elsevier B.V.

Fonte: Scopus - https://www.scopus.com/home.uri

Figura 4 - Documentos sobre impacto da pandemia da Covid-19 sobre a educação, por área de conhecimento (maio 2020).

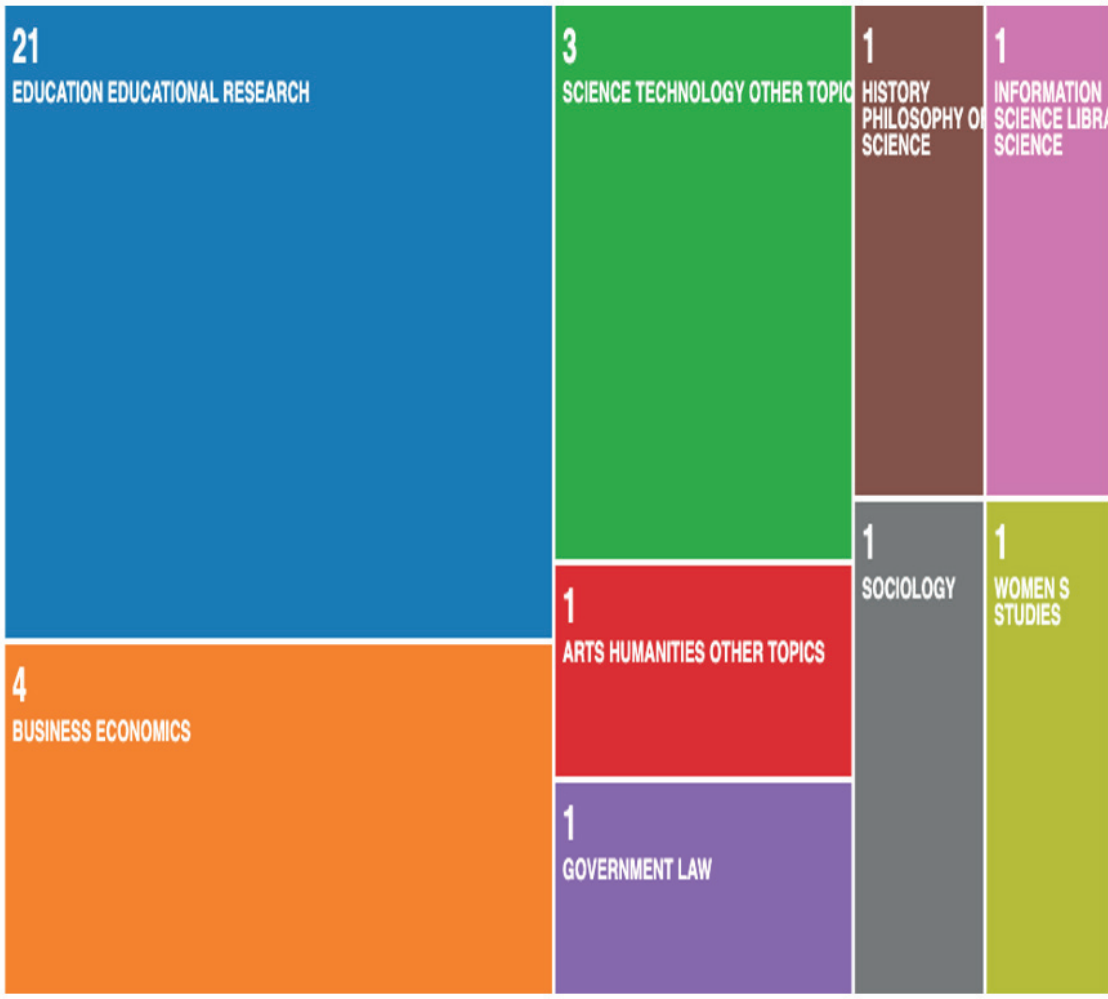

Fonte: Web of Science https://www.periodicos.capes.gov.br/?option=com_pcollection\&mn=70\&smn=79\&cid=81 
O número significativo de trabalhos na área da educação em relação às demais áreas, provavelmente é desencadeado pela inusitada realidade educacional no mundo, que demandou urgência na definição de ações para os desafios impostos pela suspensão das aulas presencias na pandemia causada pela Covid-19. Uma série de desafios impostos pelo novo formato de aulas virtuais afetou os sistemas de ensino públicos e privados, a realidade dos estudantes, professores, gestores escolares e famílias, suscitando a atenção dos profissionais e pesquisadores da área, principalmente pelos impactos nos processos educativos em contextos de desigualdades estruturais. Os textos selecionados para análise de conteúdo exemplificam problematizações e proposições registradas pelos autores, as quais revelam o panorama em discussão.

\section{b. Análise do conteúdo}

Na análise dos 20 artigos selecionados na base de busca do Google Scholar, verificou-se uma diversidade de temáticas centradas em diferentes contextos, níveis e modalidades de ensino. Os artigos abordam o ensino remoto, principalmente na educação superior, e não foram encontradas discussões relativas à educação infantil e educação de jovens e adultos. $\mathrm{O}$ ensino de áreas e conteúdos específicos é pouco discutido, pois foram encontrados 4 artigos com esta abordagem: reflexões sobre o ensino de Ciências por meio de jogos digitais na educação básica; ensino da contabilidade na educação superior; ensino da educação geográfica em tempo de pandemia; e literacias tradicionais e digitais para efetivar a qualidade do processo de ensino aprendizagem em tempos de pandemia.

Diferentes problematizações são discutidas pelos autores: democratização dos conhecimentos científico e tecnológico; falta de acesso à internet; transferência do modelo em EaD para o presencial; prejuízos à aprendizagem dos estudantes não contemplados com políticas públicas; vulnerabilidade social de alunos para as disciplinas EaD na educação superior; educação para medidas de prevenção à propagação da Covid-19; paradigma educacional pós-Covid-19 e a ressignificação do ensino; preconceito quanto à modalidade $\mathrm{EaD}$ e incentivo à sua utilização; interatividade na proposta EaD e o papel do tutor; condições do trabalho docente, temáticas da educação geográfica em tempos de pandemia; incipiência na apropriação das tecnologias digitais na educação pública; ensino remoto em instituições de educação superior caráter suplementar, mas não substitutivo.

Entre os 20 artigos, considerando o critério qualitativo e a pertinência ao debate, em relação à elucidação das categorias tecnologias digitais, trabalho docente e políticas de ensino remoto, destacam-se os artigos de Nascimento, Benedetti e Santos (2020), Santana Filho (2020) e Arruda (2020).

Ressalta-se a contribuição ao debate sobre tecnologias digitais no artigo de Nascimento, Benedetti e Santos (2020), que apresenta o uso do jogo Plague Inc. como uma proposição de relevante potencial pedagógico, no contexto do ensino remoto, da disciplina de Ciências. O jogo promove, entre outros conhecimentos, a compreensão crítica sobre o que é a saúde pública e o significado e importância de aprender conceitos e fundamentos da epidemiologia. Os autores consideram um jogo acessível a qualquer tipo de smartphone, dispensando estrutura tecnológica disponível na escola. O jogo permite várias abordagens interdisciplinares de acordo com os objetivos do professor. A discussão dos autores reforça a necessidade de os educadores utilizarem novas tecnologias com embasamento pedagógico para desenvolver a criatividade, a reflexão crítica e a cidadania responsável para enfrentamento de demandas de saúde social, como o caso da pandemia pela Covid-19.

O artigo de Santana Filho (2020) discute articuladamente os impactos do ensino remoto nas condições do trabalho docente e no uso de tecnologias digitais. $\mathrm{O}$ autor ressalta que a urgência da implantação do ensino remoto obrigou os professores a transpor o planejamento de aulas presenciais para plataformas virtuais e recursos pela internet, configurando um processo educacional focado no cumprimento de conteúdos e na realização de exercícios e atividades. A falta de domínio dos aparatos de tecnologia expõe as dificuldades e conduz os professores a trabalhar mais horas para realizar educação à distância, sendo pressionados a usar os recursos tecnológicos pessoais (computador, celular, rede de internet) e a própria casa. Assim, o trabalho docente, realizado a distância, acontece fragilizado, improvisado e sob tensão, e eles sentem-se responsabilizados pelo não domínio das novas ferramentas tecnológicas, acarretando casos de adoecimento. Sem orientação, os professores desenvolvem o 
trabalho individual sem discussão sobre a ação pedagógica, haja vista que o foco é o ensino de conteúdos em si e não a educação integral dos estudantes.

Nesse contexto, o autor aponta temáticas para uma educação geográfica contemporânea e pertinente ao tempo de pandemia, baseadas na problematização, ao tratar de, por exemplo: isolamento, adoecimentos, mortes, dinâmica global da disseminação do vírus, relação com a cadeia produtiva e de circulação de bens, mercadorias e pessoas, vida nas cidades conturbadas e condução da crise sanitária, de saúde, nos serviços essenciais e mobilidade via transporte público. O artigo traz reflexões sobre o trabalho docente e aponta relevante proposição para evitar o oferecimento acrítico das atividades remotas, que se agrava e se nutre com o distanciamento do coletivo de profissionais da escola.

A discussão apresentada por Arruda (2020) traz importantes reflexões e proposições sobre políticas educacionais para a democratização do ensino a distância de âmbito público. O autor sugere a emergência de uma política nacional de universalização de acesso à internet não mais vinculado ao acesso institucional (por meio da escola), mas a um acesso individual, em que todos as pessoas vinculadas à escola tenham este direito. Defende uma política nacional de acesso à rede de banda larga móvel, a partir de envolvimento de grupos privados de telefonia móvel que já possuem políticas de disponibilização de pacotes de dados que não contabilizam o gasto de dados em determinados aplicativos, como Whatsapp e Facebook e acesso a conteúdo educacional em sites específicos determinados por secretarias de Estado de Educação ou o Ministério da Educação. No entanto, argumenta ser necessário desconstruir a dinâmica mercantil que cerca a educação e fortalecer seu caráter público e universal. Alerta para a necessidade da participação dos profissionais da educação na discussão do acesso às tecnologias como elemento que promove a inclusão, sob o risco de favorecer o setor privado a firmar convênios com os poderes executivos da união, de estados e municípios brasileiros, para impor suas iniciativas que não representarão as necessidades e as demandas dos educadores.

O dossiê “Educação em tempos de pandemia: vozes dos sujeitos da educação básica”, edição da Revista Educação Básica em Foco, da Associação Nacional de Política e Administração da Educação (ANPAE), reúne depoimentos, vídeos, áudios e textos. Os 26 textos discutem experiências de estados e municípios brasileiros e relatos de experiências dos profissionais da educação aos desafios impostos pela pandemia do coronavírus. O conjunto de textos revela diversas realidades do ponto de vista de diferentes profissionais da educação atuantes na educação básica e ensino superior. Dos textos, foram selecionados aqueles que agregam diferentes abordagens às categorias em análise, ou seja, tecnologias digitais, trabalho docente e políticas de ensino remoto.

O conjunto de 12 textos que tratam das experiências nos Estados e Municípios brasileiros trazem informações sobre a regulamentação do ensino remoto, o plano de ação, normativas e recursos utilizados para efetividade das aulas não presenciais. São apresentadas experiências dos Estados de Distrito Federal, Goiás, Rio de Janeiro, Bahia, Mato Grosso, Mato Grosso do Sul, Minas Gerais, Espírito Santo, Alagoas, Pará, Paraíba e Tocantins. Destaca-se que a maioria dos estados definiu, para seus sistemas estaduais, a normatização de regime especial de atividades não presenciais, mediadas ou não por tecnologias, no período em que vigorar a atual situação de emergência sanitária, como possibilidade de redução da reposição de carga horária presencial pós-pandemia, conforme orienta o Parecer do CNE/CP n ${ }^{0}$ 5/2020(c).

Para exemplificar os encaminhamentos semelhantes realizados na maioria das experiências relatadas pelos autores, destaca-se o artigo de Siqueira e Gomes (2020), que apresenta o panorama das ações da Secretaria do Estado de Educação de Goiás, que adotou por determinação do Conselho Estadual de Educação (CEE), desde 23 de março de 2020, “o regime especial de aulas não presenciais” para sua rede de escolas estaduais. O regime de aulas a distância aos alunos de ensino fundamental e médio é conduzido por meio de diferentes ferramentas de ensino, como mídias digitais (plataformas de ensino próprias, whatsapp, etc.), entrega de material didático impresso (lista de exercícios, livros, etc.), acesso aos conteúdos das disciplinas/áreas via transmissão de vídeo aulas ao vivo, elaboradas pelos professores da Rede de Goiás por meio de parceria com a rede pública de comunicação (Televisão Brasil Central (TBC) e as rádios Brasil Central AM 1270 e RBC FM 90). 
Os autores problematizam a demora da Secretaria Municipal de Goiânia em definir as ações para sua rede de escolas, que só foram implantadas um mês após o decreto estadual, após cobranças dos profissionais da própria Rede e da comunidade. No entanto, a comunidade escolar e o Conselho Municipal de Educação não foram ouvidos para a formalização da proposta e definição de proposta curricular, que desconsiderou o trabalho do professor e a realidade dos alunos. O currículo da Rede pública de Goiânia foi padronizado com base na BNCC, sem a participação dos professores e da comunidade. Também, os autores relatam que a SME rescindiu, sem comunicação prévia, por meio de Decreto, o contrato de mais de 3 mil trabalhadores temporários (professores e funcionários administrativos) que atuavam nas instituições educacionais.

Os textos que tratam das experiências profissionais trazem depoimentos de 10 professores da educação básica de diferentes estados brasileiros. Sousa (2020), professor da rede pública do estado de São Paulo, relata que, apesar do empenho dos organizadores, as atividades empreendidas pela SEDUC tiveram desencontros de informações e problemas de funcionamento das plataformas. Destaca que os alunos de ensino médio apresentam uma maior participação nas aulas, mas que não há nenhuma turma onde o ensino virtual funcionou da forma prevista. Alerta que as oportunidades mercadológicas estão sendo criadas no cenário de pandemia, pois o próprio Secretário da Educação do Estado de São Paulo aponta para a utilização de um ensino híbrido pós-pandemia.

Sobre esta problemática, Santana Filho (2020) alerta que "há pouca atenção, mas uma questão em profunda disputa se encontra em franco desenvolvimento nesse contexto da pandemia: a defesa da educação à distância na educação básica”. Trata-se de um momento proveitoso para grandes empresas educacionais que encontram apoio do atual governo federal e de muitos gabinetes estaduais (SANTANA FILHO, 2020, p. 11).

Ressalta-se que, no contexto da pandemia atual, a lógica do setor financeiro neoliberal, versão dominante do capitalismo global, em marcha desde a década de 80 , colocou o mundo em crise permanente, a qual tem justificado os cortes em políticas sociais, mas legitimado a escandalosa concentração de riqueza e boicote as medidas eficazes para impedir a iminente catástrofe ecológica (SANTOS, 2020, p.5-6).

Em síntese, constata-se que considerações relatadas pelos demais autores sobre as políticas públicas criadas pelos sistemas de ensino em seus estados, como também as experiências profissionais revelam encaminhamentos e problemas comuns. São questões de impacto político-pedagógico e de condições de trabalho que revelam contradições entre interesses dos educadores e os definidos de modo autoritário pelo Estado. Este contexto demanda a interlocução entre comunidade escolar, pesquisadores, entidades representativas e sindicatos acerca das possíveis estratégias a serem implementadas, de modo a resguardar os direitos da profissionalidade docente, o princípio da gestão democrática nas escolas públicas e o destino de recursos públicos para a escola pública de qualidade.

\section{CONSIDERAÇÕES FINAIS}

A revisão sistemática da literatura revelou a expressiva quantidade de artigos produzidos na área da educação, significando relevante contribuição para a compreensão do contexto educacional frente à atual conjuntura político-educacional. As tecnologias digitais são discutidas com centralidade e compreendidas como solução do ensino remoto, cuja utilização impõe novas relações de trabalho, novos conhecimentos e políticas democráticas, demandando a atenção da categoria e de pesquisadores da área.

As problematizações apontadas por autores nacionais, no âmbito das políticas de ensino remoto, revelam a intensificação do trabalho e a responsabilização docente pela qualidade das atividades pedagógicas realizadas a distância. Os professores buscaram no imediatismo dominar os recursos tecnológicos digitais e transpor o planejamento presencial original para atividades remotas, cujo fim principal é o cumprimento dos dias letivos previstos, conforme exigências de normativas adotadas pelos sistemas de ensino e CNE. 
Autores denunciaram a pouca interlocução entre os sistemas de ensino e a comunidade educativa, quanto à definição de estratégias para a consecução do planejamento educacional e garantia do acesso democrático dos estudantes ao ensino remoto. Estes se concretizaram de modo aligeirado e improvisado, enfatizando a transmissão e reprodução de conteúdos, principalmente por meio de plataformas digitais, comprometendo as aprendizagens e a totalidade dos objetivos educacionais, nos diferentes níveis e modalidades da educação. Fazem o alerta para a oportunidade mercadológica de efetivação do ensino híbrido após a pandemia, articulado aos interesses de financiamento de empresas privadas com recursos da educação pública.

Neste sentido, há necessidade de políticas educacionais que visem a universalização de acesso institucional e individual às tecnologias e à internet, de modo a atender as demandas da educação com direito e não aos interesses do setor privado.

Importantes proposições são discutidas com o intento de valorizar o contexto do ensino remoto para a reflexão e aperfeiçoamento do currículo, formação e trabalho docente. É valorizada a revisão curricular e planejamento do ensino baseada em projetos, jogos, pesquisas que promovam a reflexão sobre as problematizações da crise sanitária, ecológica e humana, na perspectiva crítica das ciências do conhecimento.

A pandemia pelo coronavírus - Covid-19 mostra o seu impacto dramático na saúde, educação e trabalho, principalmente para a população em situação de vulnerabilidade social. O contexto em curso demanda a mobilização dos profissionais da educação no debate pedagógico sobre a qualidade do ensino e das aprendizagens, em condição de aulas não presenciais, sem perder o foco na educação como prática social que visa a formação humana para a transformação das relações excludentes e capitalistas, cada vez mais exacerbadas na contemporaneidade. A demanda é intensificar o debate crítico sobre os rumos da educação durante e pós-pandemia, a fim de combater as desigualdades sociodigitais e a precarização do trabalho docente.

Para tanto, é necessário promover o diálogo coletivo nas escolas e universidades sobre os objetivos educacionais e os encaminhamentos didático-pedagógicos que promovam a educação como direito humano para compreensão e intervenção consciente no mundo.

\section{REFERÊNCIAS}

ARRUDA, Eucidio Pimenta. Educação remota emergencial: elementos para políticas públicas na educação brasileira em tempos de Covid-19. Revista de Educação a Distância Em Rede, v. 7, n. 1, p. 257-275.

BARRETO Andreia Cristina Freitas; ROCHA Daniele Santos. Covid 19 e educação: resistências, desafios e (im) possibilidades. Revista Encantar - Educação, Cultura e Sociedade - Bom Jesus da Lapa, v. 2, p. 01-11, jan./dez. 2020.

BRASIL. Ministério da Educação. Conselho Nacional de Educação. Nota de esclarecimento. Brasília, 18 de março de 2020(a). Disponível em http://consed.org.br/media/download/5e78b3190caee.pdf. Acesso em: 20 jul. 2020.

BRASIL. Medida Provisória n. 934, de 1 de abril, 2020(b). Estabelece normas excepcionais sobre o ano letivo da educação básica e do ensino superior decorrentes das medidas para enfrentamento da situação de emergência de saúde pública de que trata a Lei $\mathrm{n}^{\circ}$ 13.979, de 6 de fevereiro de 2020. Disponível em: http://www.in.gov.br/ en/web/dou/-/medida-provisoria-n-934-de-1-de-abril-de-2020-250710591 Acesso em: 20 jul.2020.

BRASIL. Ministério da Educação. Conselho Nacional de Educação. Parecer n 5 de 28 de abril de 2020(c). Reorganização do calendário escolar e da possibilidade de cômputo de atividades não presenciais para fins de cumprimento da carga horária mínima anual, em razão da Pandemia da COVID-19. Disponível em: http:// portal.mec.gov.br/index.php?option=com_docman\&view=download\&alias=145011-pcp005-20\&category_ slug=marco-2020-pdf\&Itemid=30192 Acesso em: 20 jul. 2020. 
LUCIO-ARIAS, Diana; VELEZ-CUARTAS, Gabriel; LEYDESDORFF, Loet. SciELO citation index and web of science: Distinctions in the visibility of regional science. Disponível em: http://www. issi2015. org/files/ downloads/all-papers/1152.pdf. Acesso em: 10 jul. 2020.

KAUCHAKJE, Samira; ROSA, Maria Arlete. Produção do Conhecimento: a prática da revisão sistemática da literatura. v.1. Curitiba: UTP, 2020. (no prelo).

MARTINS. Ronei Ximenes. Covid 19 e o fim da educação a distância: um ensaio. Em Rede, v. 7, n. 1, p. 242256, jan./jun. 2020.

MATTEI, Lauro. A crise econômica decorrente da Covid-19 e as ações da equipe econômica do governo atual. Texto para discussão (NECAT), nº35. Santa Catarina, Centro socioeconômico da Universidade Federal de Santa Catarina, 2020. Disponível em: https://drive.google.com/file/d/1COp-CN4Od31hF_8Jo1UHiUV8vLKdDqav/ view Acesso em: 25 out. 2020.

NASCIMENTO, Francisca Georgiana Martins do; BENEDETTI, Tiago Rodrigues; SANTOS, Adriana Ramos dos. Uso do Jogo Plague Inc.: uma possibilidade para o Ensino de Ciências em tempos da COVID-19. Brazilian Journal of Development, Curitiba, v. 6, n. 5, p. 25909-25928, maio 2020.

NEVES, Vanessa Ribeiro; SANNA, Maria Cristina. Ensino da liderança em enfermagem: um estudo bibliométrico. Acta Paul Enferm 25, no. 2 (2012), p. 308-13.

O’BLENIS, Peter. 5 Best Practices for Optimizing Your Systematic Review. Evidence Partners, 2017. Disponível em: https://blog.evidencepartners.com/5-best-practices-for-optimizing-your-systematic-reviews. Acesso em: 24 out. 2020.

OKOLI, Chitu. A guide to conducting a standalone systematic literature review. EaD Em Foco, v.9, n. 1, p. 1- 40, 2019. SANTA, Samaly; HERRERO-SOLANA, Víctor. Cobertura de la ciencia de América Latina y el Caribe en Scopus vs Web of Science. Investigación bibliotecológica, v.24, n.52, p.13-27, 2010.

SANTOS, Boaventura Souza. A cruel Pedagogia do vírus. Coimbra: Edições Almedina, 2020.

SANTANA FILHO, Manoel Martins de. Educação geográfica, docência e o contexto da pandemia COVID-19. Revista Tamoios, São Gonçalo (RJ), ano 16, n. 1, Especial COVID-19. p. 3-15, maio 2020.

SIQUEIRA, Romilson Martins; GOMES Marcilene Pelegrine. Panorama geral das ações desenvolvidas pela Secretaria de Estado de Educação de Goiás e pela Secretaria Municipal de educação de Goiânia em tempos de pandemia. Revista Educação Básica em Foco (ANPAE), v.1, n.1, abr./jun. 2020.

SOUSA, Fernando Martins Parreira e. Educação em tempos de pandemia: infelicidade de muitos, oportunidade de mercado para poucos. Revista Educação Básica em Foco (ANPAE), v.1, n1, abr./jun. 2020. 